\title{
Efficacy and feasibility of a novel and noninvasive computed tomography-guided marking technique for peripheral pulmonary nodules
}

\author{
Yosuke Matsuura, MD, Mingyon Mun, MD, PhD, Ken Nakagawa, MD, and Sakae Okumura, MD, \\ Tokyo, Japan
}

Thoracoscopic surgery is an option to diagnose small peripheral pulmonary nodules (SPPNs). In some cases, intraoperative localization is difficult because of lesion size or distance from the pleura, and the time required for intraoperative localization is prolonged. In such cases, preoperative marking is useful.

Percutaneous computed tomography (CT)-guided hookwire placement ${ }^{1}$ is the most common method of preoperative marking. It is a relatively easy technique but it is sometimes accompanied by critical complications, especially air embolism, resulting from puncture of the visceral pleura (VP). ${ }^{2} \mathrm{To}$ avoid catastrophic complications, several marking techniques without puncture of the VP can be performed. ${ }^{3-5}$

From the Department of Thoracic Surgical Oncology, Cancer Institute Hospital of the Japanese Foundation for Cancer Research, Tokyo, Japan.

Disclosures: Authors have nothing to report with regard to commercial support

Received for publication Sept 29, 2014; revisions received Nov 6, 2014; accepted for publication Nov 15, 2014; available ahead of print Dec 20, 2014.

Address for reprints: Mingyon Mun, MD, PhD, Department of Thoracic Surgical Oncology, Cancer Institute Hospital of the Japanese Foundation for Cancer Research, 3-8-31, Ariake, Koto-ku, Tokyo 135-8550, Japan (E-mail: mingyon. mun@jfcr.or.jp).

J Thorac Cardiovasc Surg 2015;149:1208-9

$0022-5223 / \$ 36.00$

Copyright (C) 2015 by The American Association for Thoracic Surgery

http://dx.doi.org/10.1016/j.jtcvs.2014.11.040

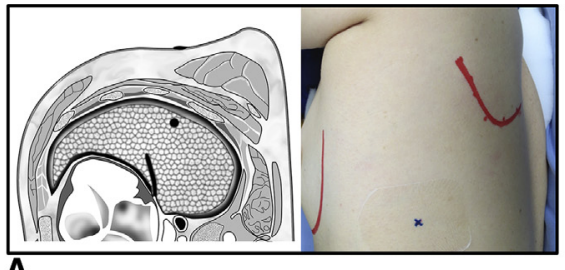

A

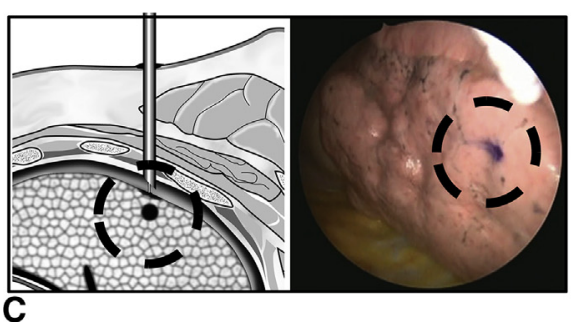

Encouraged by these initial reports, we developed a novel marking technique called noninvasive CT-guided pulmonary marking (NICTM).

\section{MATERIALS AND METHODS}

Twenty patients with 20 nodules underwent NICTM. Our institutional review board approved the procedure, and written informed consent was obtained in all cases. The indications for NICTM were histologically undiagnosed SPPNs that appeared resectable by thoracoscopic wedge resection (ie, $\leq 20 \mathrm{~mm}$ in size).

Preoperative CT scans were performed 1 day before the operation. Scans were obtained at maximal expiratory phase. Patients were in the lateral position to best approximate their position during the thoracoscopic procedure, using roentgenopaque markers on the body surface. A mark was placed by surgeons on a patient's skin at the shortest distance from the nodule (Figure 1, A). To prevent the mark from dislodging, we covered it with a waterproof tape. When ribs and/or scapulae interfered with marker placement, the mark was shifted toward the nodule in the same plane of the CT sectional image. Patients received general anesthesia and were placed in the lateral position for surgery. The relevant lung was collapsed and the thoracic cavity was entered through either 1 or 2 trocar ports. A 16-gauge indwelling catheter (Surflo, Termo Corporation, Tokyo, Japan) was inserted vertically from the skin mark through the chest wall and into the thoracic cavity (Figure 1, B). The needle was removed and the external catheter hub was fixed to the thoracic wall. After inflation of the lung, a $\varphi 1.0 \mathrm{~mm}$ polyurethane epidural catheter (Hakko Medical, Tokyo, Japan) with pyoktanin blue pigment was inserted through the indwelling catheter (Figure 1,C). When the tip of the tattooing catheter touched the reinflated lung, surgeons could detect resistance and know to stop advancing it.

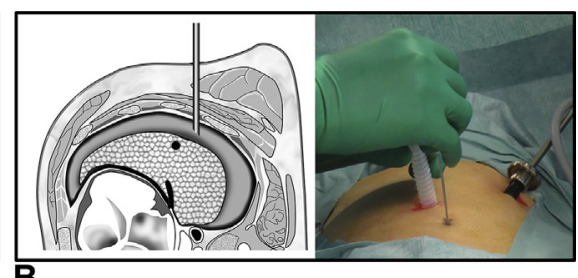

$\mathbf{B}$ (1) 
TABLE 1. Patient characteristics and results in this series

\begin{tabular}{lc}
\hline \multicolumn{1}{c}{ Characteristic } & Result $(\mathbf{N}=\mathbf{2 0})$ \\
\hline Gender & Male $(\mathrm{n}=11) / \mathrm{female}(\mathrm{n}=9)$ \\
Age, $\mathrm{y}^{*}$ & $65(29-79)$ \\
Body mass index* & $23(19-30)$ \\
Thickness of chest wall measured on & $34(18-80)$ \\
$\quad$ computed tomography scan, $\mathrm{mm}^{*}$ & $12(3-18)$ \\
Tumor size, $\mathrm{mm} \dagger$ & $3.9(0-17)$ \\
Distance from the visceral pleura, mm $\dagger$ & Yes $(\mathrm{n}=6) / \mathrm{no}(\mathrm{n}=14)$ \\
Involving the visceral pleura & Primary lung cancer $(\mathrm{n}=10)$ \\
& Metastatic lung cancer $(\mathrm{n}=8)$ \\
Histology & Benign lesion $(\mathrm{n}=2)$ \\
& $69(49-116)$ \\
Operative time, min $\dagger$ & $3(1-6)$ \\
Intraoperative procedure time, min $\dagger$ & $6.5(0-14)$ \\
Distance from the nodule to the marking & \\
point, mm $\dagger$ & \\
*Values are presented as median (range). $\dagger$ Values are mean (range).
\end{tabular}

Pigmentation of the VP was visually identified after deflation of the lung. We palpated around the marking point using a finger through the port site, confirming the presence of nodule. Subsequently, wedge resection was performed using an automatic stapler.

\section{RESULTS}

The patient characteristics and results are shown in Table 1. All nodules were identified near the marking point. Wedge resection was successful in all cases. No complications were observed during the marking procedure.

\section{DISCUSSION}

When preoperative marking is not conducted, the time required for intraoperative localization is sometimes prolonged. Hence, visual inspection and palpation based on pigment of the VP can reduce this time. In our own data, NICTM slightly shortened the average operative time for wedge resection from 75 minutes (range, 38-181 minutes) to 69 minutes (range, 49-116 minutes) (Table 1).

Recently, several groups have reported on marking techniques that avoid puncture of the VP. ${ }^{3-5}$ One technique used a small, round cotton ball to stamp on the VP. ${ }^{3,4}$ NICTM has some advantages over this technique. First, NICTM uses a $\varphi 1.0 \mathrm{~mm}$ catheter instead of a small, round cotton ball to mark on the VP with well-defined point (Figure 1,C) because the cotton ball method has the risk of pigment spreading throughout the pleural cavity impairing marking precision. Second, because NICTM can be accomplished with a catheter by single puncture, the time needed for the process is minimized. Consequently, we think NICTM is more suitable where there are multiple nodules. Another technique used navigational bronchoscopy. ${ }^{5}$ This technique marks quickly and reliably for multiple nodules; however, it needs special equipment and skills.

Moreover, the results in our series suggest that the arrangements for NICTM are not strongly affected by patient characteristics (Table 1). However, when targeted lesions are difficult to palpate due to their distance from the VP, it is not easy to identify their location using NICTM only. In lesions located $>30 \mathrm{~mm}$ from the VP, designed segmentectomy should be encouraged.

\section{CONCLUSIONS}

NICTM is a simple and easy marking technique for SPPNs when difficulty in recognition is anticipated.

The authors thank Dr Tatsuya Nishida and Dr Masaya Kawada for providing helpful advice and suggestions. The authors also thank Shigeyuki Sakaguchi of Clark Kent Co Ltd for assisting with the illustrations.

\section{References}

1. Wicky S, Dusmet M, Doenz F, Ris HB, Schnyder P, Portier F. Computed tomography-guided localization of small lung nodules before video-assisted resection: experience with an efficient hook-wire system. J Thorac Cardiovasc Surg. 2002;124:401-3

2. Sakiyama S, Kondo K, Matsuoka H, Yoshida M, Miyoshi T, Yoshida S, et al. Fatal air embolism during computed tomography-guided pulmonary marking with a hook-type marker. J Thorac Cardiovasc Surg. 2003;126:1207-9.

3. Kawada M, Okubo T, Poudel S, Suzuki Y, Kawarada Y, Kitashiro S, et al A new marking technique for peripheral lung nodules avoiding pleural puncture the intra-thoracic stamping method. Interact Cardiovasc Thorac Surg. 2013;16: 381-3.

4. Nishida T, Fujii Y, Akizuki K. Preoperative marking for peripheral pulmonary nodules in thoracoscopic surgery: a new method without piercing the pulmonary parenchyma. Eur J Cardiothorac Surg. 2013;44:1131-3.

5. Sato M, Omasa M, Chen F, Sato T, Sonobe M, Bando T, et al. Use of virtual assisted lung mapping (VAL-MAP), a bronchoscopic multispot dye-marking technique using virtual images, for precise navigation of thoracoscopic sublobar lung resection. J Thorac Cardiovasc Surg. 2014;147:1813-9. 